\title{
Atypical aleukemic presentation of large granular lymphocytic leukemia: a case report
}

This article was published in the following Dove Press journal:

OncoTargets and Therapy

19 December 2016

Number of times this article has been viewed

\author{
Cristina Bagacean ${ }^{1,2}$ \\ Adrian Tempescul ${ }^{3}$ \\ Mariana Patiul,4 \\ Bogdan Fetica ${ }^{4}$ \\ Horia Bumbea ${ }^{5, *}$ \\ Mihnea Zdrenghea ${ }^{1,4, *}$ \\ 'Department of Hematology, Iuliu \\ Hatieganu University of Medicine \\ and Pharmacy, Cluj-Napoca, Romania; \\ ${ }^{2}$ Laboratory of Immunology and \\ Immunotherapy, University Hospital \\ Brest, ${ }^{3}$ Department of Hematology, \\ Institute of Cancerology and \\ Hematology, Brest University Medical \\ School, Brest, France; ${ }^{4}$ Department of \\ Hematology, Ion Chiricuta Oncology \\ Institute, Cluj-Napoca, ${ }^{5}$ Department \\ of Hematology, Carol Davila \\ University of Medicine and Pharmacy, \\ Bucharest, Romania \\ *These authors contributed equally \\ to this work
}

\begin{abstract}
Large granular lymphocytic leukemia (LGLL) is a rare lymphoproliferative disorder of transformed natural killer or T-cells attributed to chronic exposure to the proinflammatory cytokine IL-15. Diagnosis of the majority of T-cell LGLL is established by documenting clonal large granular lymphocytes (LGLs) in peripheral blood, by morphology and immunophenotype. The proteasome inhibitor bortezomib is known to target molecular pathways downstream of the IL-15 receptor signaling and has been proposed as a therapy in these patients. We report an uncommon presentation of LGLL with chronic neutropenia lacking typical blood LGLs, which failed to respond to bortezomib but obtained a very good partial remission with a classical methotrexate regimen.
\end{abstract}

Keywords: large granular lymphocytes, lymphoproliferative, Felty, neutropenia, bortezomib

\section{Introduction}

T-cell large granular lymphocytic leukemia (T-LGLL) is a rare lymphoproliferative disease characterized by the accumulation of a monoclonal T- or natural killer (NK)lymphocyte population in the bone marrow, blood, spleen, and liver. ${ }^{1,2}$

Large granular lymphocytes (LGLs) are large white blood cells (WBCs) with reniform or round nuclei and abundant cytoplasm, which typically contains azurophilic granules. In normal adults, LGLs account for up to $10 \%-15 \%$ of peripheral blood mononuclear cells. ${ }^{3}$ This population can be further classified into the following two different lineages of lymphocytes based on their cell surface markers: $\mathrm{CD}^{-}{ }^{-} \mathrm{NK}$ cells and $\mathrm{CD}^{+}$cytotoxic T-lymphocytes. ${ }^{4,5}$

Current World Health Organization (WHO) classification recognizes the following three distinct disorders of LGLs: T-LGLL, chronic lymphoproliferative disorders of NK cells (CLPD-NK), and aggressive NK-cell leukemia. Despite the different cellular origin, there is considerable overlap between T-LGLL and CLPD-NK in terms of clinical presentation and response to therapy. ${ }^{6,7}$

T-LGLL and CLPD-NK are indolent diseases frequently associated with cytopenias and a wide spectrum of autoimmune manifestations. ${ }^{8}$ Neutropenia can lead to recurrent bacterial infections, representing an indication for treatment initiation in most of the cases. ${ }^{9}$ Immunosuppressive therapies are usually used in this context, including methotrexate, cyclophosphamide, and cyclosporine. ${ }^{10}$

With the advent of potential new therapeutic options, a recent surge in the interest for the pathophysiology of these diseases is noted. ${ }^{5}$ We here report an uncommon presentation of T-LGLL, where the diagnosis was missed because of the lack of the typical appearance of circulating and bone marrow LGLs.
Correspondence: Mihnea Zdrenghea Department of Hematology, lon Chiricuta Oncology Institute, 73, 2I Decembrie Boulevard, 400I 24 Cluj-Napoca, Romania $\mathrm{Tel}+4074$ I 100480

$\mathrm{Fax}+40264598606$

Email mzdrenghea@umfcluj.ro
OncoTargets and Therapy 2017:10 31-34

(c) (1) (2) ๑ 2017 Bagacean et al. This work is published and licensed by Dove Medical Press Limited. The full terms of this license are available at https:/www.dovepress.com/terms.php cc) hereby accept the Terms. Non-commercial uses of the work are permitted without any further permisision from Dove Medical Press Limited, provided the work is properly attributed. For permission for commercial use of this work, please see paragraphs 4.2 and 5 of our Terms (https://www. doverperess.com/terms.php). 


\section{Case report}

A 60-year-old Caucasian woman was referred to the Department of Hematology of Ion Chiricuta Oncology Institute because of recurrent respiratory and urinary infections and with a diagnosis of chronic leukopenia. She had a documented history of neutropenia with absolute neutrophil count $<1 \mathrm{G} / \mathrm{L}$ for $>6$ years, but no abnormal cells were noted on past cytological blood and bone marrow examinations.

On admission, clinical appearance was normal except for a palpable spleen. Abdominal ultrasound described an enlarged spleen of $172 / 60 \mathrm{~mm}$ with a $90 \mathrm{~cm}^{2}$ surface. A chest abdomen pelvis computed tomography scan described mild hepatosplenomegaly with no lymph node enlargement. Blood tests confirmed leukopenia with severe neutropenia and lymphopenia (WBC $0.88 \mathrm{G} / \mathrm{L}$, neutrophils $0.28 \mathrm{G} / \mathrm{L}$, and lymphocytes $0.3 \times \mathrm{G} / \mathrm{L}$ ) and mild normocytic anemia (hemoglobin $112 \mathrm{~g} / \mathrm{L}$ and mean corpuscular volume $88 \mathrm{fL}$ ) and thrombocytopenia $(122 \times \mathrm{G} / \mathrm{L})$. The reticulocyte count was slightly increased, as were lactate dehydrogenases and unconjugated bilirubin levels. Direct Coombs' test was negative, but haptoglobin was low and cold agglutinins were detected. The presence of cryoglobulins was also revealed. Serum protein immunofixation electrophoresis was negative for monoclonality, as was screening for viral infections (CMV, EBV, HTLV, and HIV) and autoimmunity (rheumatoid factor, anti-double-stranded DNA antibodies, and antinuclear autoantibodies, the latter at the upper limit of normal). No atypical cells were noted on the peripheral blood smear.

Examination of the bone marrow identified a population of atypical lymphocytes, but no azurophilic granules were described. The infiltrate was difficult to quantify because of the presence of $>90 \%$ smudge cells (Figure 1). The lymphocytic

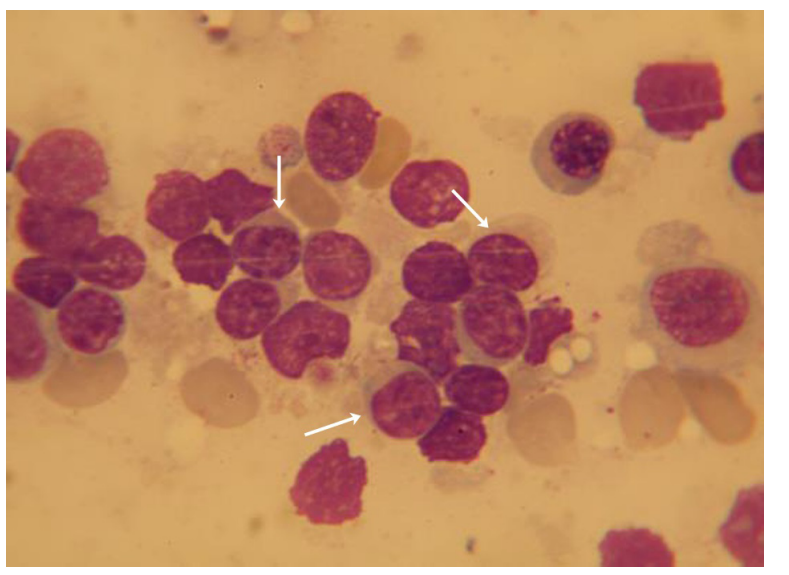

Figure I Bone marrow examination showing infiltrate with cells of lymphoid morphology, intact (arrows), or smudged.

Note: No azurophilic granules are observed (bone marrow - May-GrunwaldGiemsa stain, $\times 100$ magnification). infiltration was identified by bone marrow flow cytometry as including a $20 \%$ population of atypical suppressor $\mathrm{CD}^{+} /$ $\mathrm{CD}^{+} / \mathrm{CD}^{-}$T-cells, coexpressing CD7, CD43, and CD2. A bone marrow biopsy confirmed the presence of an infiltration with lymphocytes of the above phenotype, described as large cells with an abundant cytoplasm. This immunophenotype is compatible with the expression of LGL surface markers, and the aberrant lack of CD5 expression sustained the clonality of the mentioned population (Figure 2).

The patient was diagnosed with T-LGLL, secondary cryoglobulinemia, and associated cold agglutinin hemolytic anemia. Treatment with corticosteroids (prednisone $1 \mathrm{mg} / \mathrm{kg}$ ) was initiated. After 4 weeks, there was no response and, in the presence of recurrent respiratory infection symptoms, we decided to opt for a therapy that could yield a rapid response. Thus, a second-line treatment with bortezomib associated with dexamethasone (bortezomib $1.3 \mathrm{mg} / \mathrm{m}^{2}$ intravenous on days $1,4,8$, and 11 and dexamethasone $40 \mathrm{mg}$ /day intravenous on days 1-4 and 8-11) was initiated. The patient underwent two cycles of therapy, with no biological or clinical response. She required hospitalization in our department four times during the two chemotherapy cycles for microbiologically negative febrile neutropenia, treated with broad-spectrum antibiotics and granulocyte-colony stimulating factor. Subsequently, treatment with low-dose methotrexate $\left(10 \mathrm{mg} / \mathrm{m}^{2} /\right.$ week orally) was commenced with a partial response that was rapidly acquired and maintained. The patient continues to have a very good partial response, with a stable absolute neutrophil count of $>1 \mathrm{G} / \mathrm{L}$, and did not present any clinically manifest infections requiring antibiotics or hospitalization for over 2 years.

\section{Discussion}

Historically, a circulating LGL count of $>2 \mathrm{G} / \mathrm{L}$ was considered as mandatory for the diagnosis of large granular lymphocytic leukemia (LGLL), but current diagnostic requirements lowered this threshold to $>0.4$ or $0.5 \mathrm{G} / \mathrm{L}$ together with a suggestive clinical presentation, which may include splenomegaly, cytopenias including neutropenia and/or anemia, and autoimmune diseases. For T-LGLL, an activated T-cell phenotype is expected, expressing CD3, CD8, CD57, and/or CD16, demonstrated by flow cytometry and/or bone marrow biopsy. T-cell clonality assays are an important contributor toward diagnosis. ${ }^{4}$

Our observation reports an unusual presentation of a very rare disease. The particularity of the case is the absence of circulating LGLs, no cytoplasmic azurophilic granules in the bone marrow LGLs, and the particular treatment choice. 

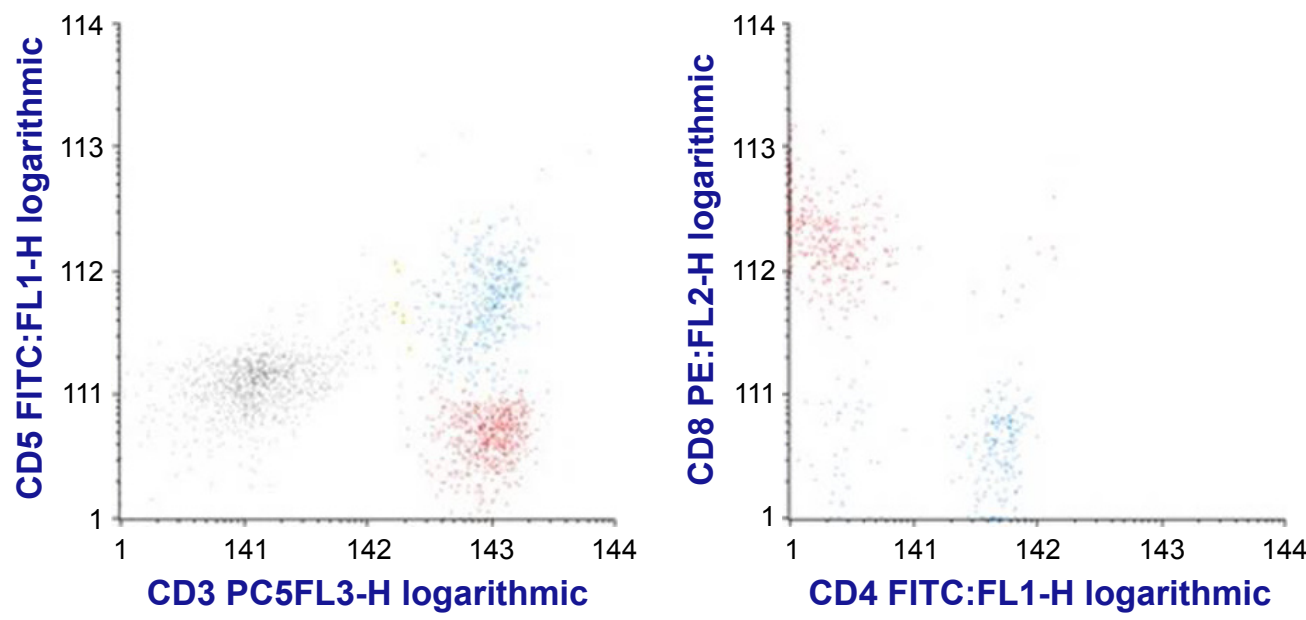

Figure 2 Dot plot histograms showing atypical suppressor $\mathrm{CD5} 5^{-} \mathrm{CD} 3^{+} \mathrm{CD} 8^{+} \mathrm{T}$ cells (in red) and normal $\mathrm{CD} 3^{+} \mathrm{CD} 5^{+} \mathrm{T}$-cells (blue).

Notes: FACSCalibur acquisition with CellQuest acquisition software of bone marrow aspirate leukocytes marked with a monoclonal antibody panel including CD3 PC5, CD4 FITC, CD5 FITC, and CD8 PE. Infinicyt 7.0 software was used for analysis.

Our patient did not display any atypical lymphocytes in the peripheral blood. On the contrary, she presented lymphopenia with normal lymphocytic morphology. She did not respond to proteasome inhibitor treatment, although bortezomib is known to target some of the pathways implicated in the pathogenesis of this disease.

An evolution similar to our patient's is seen in Felty's syndrome, condition with a pathogenesis closely related to LGLL as both diseases have a common genetic determinant, the HLA-DR4 haplotype. ${ }^{11}$ Classically, the criteria for Felty's syndrome required the triad rheumatoid arthritis, leukopenia, and splenomegaly. ${ }^{12}$ Nowadays, leukopenia is clearly defined as neutropenia, and it became clear that patients displaying only rheumatoid arthritis and neutropenia have a similar clinical evolution regardless of the presence or absence of splenic enlargement. ${ }^{12}$ A total of $11 \%-36 \%$ of LGLL patients have been reported to have rheumatoid arthritis, and $30 \%-40 \%$ of the patients diagnosed with Felty's syndrome have LGL expansion. , $^{1,13,14}$

A new vision unifying the hematologic and rheumatologic pathologies could improve the treatment of LGLL and warrants the consideration of different interesting therapeutic options. Patients with unexplained neutropenia with or without serologically positive rheumatoid arthritis should be tested for circulating or bone marrow LGLs.

Interestingly, LGLL has also been reported to be associated with B-cell lymphoproliferations. In a single-center study reviewing 126 patients with LGL leukemia or expansion, $39.4 \%$ of patients also presented a lymphoproliferative disease including monoclonal gammopathy of unknown significance and monoclonal B-cell lymphocytosis, either concomitantly or developed shortly after LGLL diagnosis. Conversely, $14.2 \%$ of the patients had a documented previous B-cell lymphoproliferative disease, including diffuse large B-cell, Burkitt's, and mantle cell lymphomas, chronic lymphocytic leukemia, multiple myeloma, and hairy cell leukemia. ${ }^{15}$

Concerning the treatment choice in our patient, as far as we know, there is only one report of a patient with T-LGLL treated with bortezomib, and in the case reported the patient had a rapid complete hematological response. ${ }^{16}$ Our patient had no response to bortezomib, but she responded rapidly to immunosuppressive doses of methotrexate. However, this does not demonstrate the inefficacy of bortezomib, and we find the hypothesis of bortezomib targeting the dysregulated pathways in LGLL as appealing.

In this group of diseases, there are multiple survival signaling pathways activated, such as the JAK/STAT3, sphingolipid, and Ras/MEK/ERK pathways, adding further complexity to treatment options. ${ }^{17,18}$ Because some patients are refractory to currently available treatments and none of these therapeutic modalities can cure T-LGLL, new therapeutic options are needed. ${ }^{19}$ No standard therapy has yet been established because of the lack of large, prospective trials.

\section{Conclusion}

LGLL is a rare clonal disorder of T-lymphocytes with a complex biological and clinical appearance, which makes diagnosis a challenge. As seen in our case, circulating LGLs can be absent, as do LGL cytoplasmic azurophilic granules. Therefore, unexplained neutropenia should be further investigated for a possible LGLL. 
There are no curative therapeutic modalities, and it is fairly well accepted that the treatment of choice is immunosuppression. All the molecular pathways recently recognized to be involved in this disease have opened perspectives on new potential therapeutic targets. Bortezomib and splenectomy are options worth considering. The rarity of the disease, however, makes prospective trials difficult to implement.

\section{Acknowledgments}

Drs CB and MZ are supported by a grant from the Romanian National Authority for Scientific Research, CNCS UEFISCDI (Project number PN-II-RU-TE-2014-4-2074). The patient gave written consent for the use of her anonymized data for scientific purposes.

\section{Disclosure}

The authors report no conflicts of interest in this work.

\section{References}

1. Loughran TP Jr. Clonal diseases of large granular lymphocytes. Blood. 1993;82(1):1-14.

2. Watters RJ, Liu X, Loughran TP Jr. T-cell and natural killer-cell large granular lymphocyte leukemia neoplasias. Leuk Lymphoma. 2011; 52(12):2217-2225.

3. Zhang D, Loughran TP Jr. Large granular lymphocytic leukemia: molecular pathogenesis, clinical manifestations, and treatment. Hematology Am Soc Hematol Educ Program. 2012;2012:652-659.

4. Lamy T, Loughran TP Jr. How i treat LGL leukemia. Blood. 2011; 117(10):2764-2774.

5. Lazaro E, Duffau P, Chaigne Delalande S, Greib C, Pellegrin JL, Viallard JF. [Large granular lymphocyte leukemia: clinical and pathogenic aspects]. Rev Med Interne. 2013;34(5):553-560.

6. Dearden C. Large granular lymphocytic leukaemia pathogenesis and management. Br J Haematol. 2011;152(3):273-283.
7. Leblanc F, Zhang D, Liu X, Loughran TP. Large granular lymphocyte leukemia: from dysregulated pathways to therapeutic targets. Future Oncol. 2012;8(7):787-801.

8. Bockorny B, Dasanu CA. Autoimmune manifestations in large granular lymphocyte leukemia. Clin Lymphoma Myeloma Leuk. 2012;12(6): 400-405.

9. Autrel-Moignet A, Lamy T. Autoimmune neutropenia. Presse Med. 2014;43(4 Pt 2):e105-e118.

10. Loughran TP Jr, Zickl L, Olson TL, et al. Immunosuppressive therapy of LGL leukemia: prospective multicenter phase II study by the Eastern Cooperative Oncology Group (E5998). Leukemia. 2015; 29(4):886-894.

11. Starkebaum G, Loughran TP Jr, Gaur LK, Davis P, Nepom BS. Immunogenetic similarities between patients with Felty's syndrome and those with clonal expansions of large granular lymphocytes in rheumatoid arthritis. Arthritis Rheum. 1997;40(4):624-626.

12. Burks EJ, Loughran TP Jr. Pathogenesis of neutropenia in large granular lymphocyte leukemia and Felty syndrome. Blood Rev. 2006; 20(5):245-266.

13. Sokol L, Loughran TP Jr. Large granular lymphocyte leukemia. Oncologist. 2006;11(3):263-273.

14. Bowman SJ, Bhavnani M, Geddes GC, et al. Large granular lymphocyte expansions in patients with Felty's syndrome: analysis using anti-T cell receptor V beta-specific monoclonal antibodies. Clin Exp Immunol. 1995;101(1):18-24.

15. Skarbnik AP, Portell CA, Maciejewski JP, et al. Association of large granular lymphocytic leukemia (LGL) with B-cell lymphoproliferative disorders. Blood. 2013;122:1387.

16. Pelliccia S, Di Napoli A, Naso V, Alma E, Rebecchini C, Cox MC. Very long-lasting remission of refractory T-large granular lymphocytes leukemia and myeloma by lenalidomide treatment. Eur J Haematol. 2013;91(2):183-186.

17. Steinway SN, LeBlanc F, Loughran TP Jr. The pathogenesis and treatment of large granular lymphocyte leukemia. Blood Rev. 2014; 28(3):87-94.

18. Rajala HL, Porkka K, Maciejewski JP, Loughran TP Jr, Mustjoki S. Uncovering the pathogenesis of large granular lymphocytic leukemianovel STAT3 and STAT5b mutations. Ann Med. 2014;46(3):114-122.

19. Koskela HL, Eldfors S, Ellonen P, et al. Somatic STAT3 mutations in large granular lymphocytic leukemia. N Engl J Med. 2012;366(20): 1905-1913.
OncoTargets and Therapy

\section{Publish your work in this journal}

OncoTargets and Therapy is an international, peer-reviewed, open access journal focusing on the pathological basis of all cancers, potential targets for therapy and treatment protocols employed to improve the management of cancer patients. The journal also focuses on the impact of management programs and new therapeutic agents and protocols on

\section{Dovepress}

patient perspectives such as quality of life, adherence and satisfaction. The manuscript management system is completely online and includes a very quick and fair peer-review system, which is all easy to use. Visit http://www.dovepress.com/testimonials.php to read real quotes from published authors. 